\title{
Unusual Presentation of Precocious Puberty Associated with Primary Hypothyroidism in a 8.5 Years Old Girl
}

\author{
Shamsun Naher Rikta ${ }^{1}$, Fatema Ashraf ${ }^{2}$, Samira Areen ${ }^{3}$
}

\begin{abstract}
Precocious puberty is one of the gynaecological problems in childhood. Children with hypothyroidism generally have delayed pubertal development. But primary hypothyroidism is one of the rare causes of precocious puberty especially in long standing untreated patients. Bilateral ovarian enlargement due to multiple cystic ovaries is a rare complication of primary hypothyroidism. For ovarian enlargement no treatment is required at all. This is a case report of an 8.5 years old girl diagnosed as a case of precocious puberty with benign ovarian tumour at a peripheral hospital and was being prepared to undergo laparotomy. When patient was admitted at Shaheed Suhrawardy Medical College Hospital (ShSMCH), Dhaka, Bangladesh, after thorough investigations primary hypothyroidism was diagnosed. She was given thyroxin replacement and close monitoring was done by doing USG of uterus and adnexae, thyroid function test at monthly interval. USG after 2 months revealed significant reduction of ovarian volume and at 6 month ovarian volume reduced to normal. It was also noticed that the rate of reduction of ovarian volume corresponds to the rate of reduction of serum TSH level measured serially at every 2 months interval.
\end{abstract}

Keywords: Precocious puberty; primary hypothyroidism; ovarian enlargement.

Delta Med Col J. Jul 2018;6(2): 102 - 105

\section{Introduction}

Precocious puberty is one of the common excess production of androgen from ovary and gynaecological problems in childhood. ${ }^{1}$ It may be GnRH dependent or isosexual where symptoms adrenals. ${ }^{1,2}$ When any girl under 8 years of age presents with breast and pubic hair development, needs careful history taking and physical are due to excess production of estrogen and all the changes of puberty comes sequentially (thelarche, adrenarche, menarche), and GnRH independent or pseudo precocious puberty or heterosexual where pubertal changes are due to examination with minimal evaluation of bone age and close follow up to determine linear growth. ${ }^{2}$ GnRH dependent precocious puberty mostly are constitutional due to premature activation of

1. Assistant professor (CC), Dept. of Gynaecology and Obstetrics, Delta Medical College, Dhaka, Bangladesh.

2. Professor and Head, Dept. of Gynaecology and Obstetrics, Shaheed Suhrawardy Medical College, Dhaka, Bangladesh.

3. Registrar, Dept. of Gynaecology and Obstetrics, Delta Medical College, Dhaka, Bangladesh.

Correspondence: Dr. Shamsun Naher Rikta. e-mail: Shamsunnaherrikta@gmail.com 
hypothalamo pituitary ovarian axis. ${ }^{3}$ Others are due to primary hypothyroidism, intracranial lesions, etc. ${ }^{4}$ Association of primary hypothyroidism with precocious pubety is that there is a hormonal overlap in pituitary feedback mechanism. When TSH level is high it stimulates FSH receptors of ovary producing high amount of estrogen which causes bilateral enlargement of ovary and periodic menstrual bleeding. ${ }^{3}$ Diagnosis is made by blood (routine investigations, thyroid function tests, thyroid antibody, tumour marker), USG of abdomen and thyroid gland, CT Scan of abdomen and brain, and MRI of brain to exclude any intracranial pathology. So in any girl presenting with bilateral enlargement of ovary with periodic per vaginal bleeding, primary hypothyroidism must be excluded. Due to lack of experience and scarce data regarding this issue there is every chance to commit an unnecessary oophorectomy or cystectomy, where the treatment can be successfully done by only giving oral thyroxin replacement.

\section{Case Report}

Amena, an 8.5 years old girl of a lower middle class family, third issue of non consanguineous parents hailing from Sirajganj was admitted in Shaheed Suhrawardy Medical College Hospital (ShSMCH) with the complaints of periodic irregular per vaginal bleeding for 1 year, lump in lower abdomen and generalized weakness for 1 year. The amount of bleeding was scanty, and occured at 15 to 45 days interval. There was no history of local trauma, or discharge, bleeding from any other site or foreign body insertion. There was no history to suggest prior central nervous system insult, raised intracranial pressure, polyuria, polydipsia, or ingestion of hormonal preparations. There was no family history of a thyroid disorder, or precocious puberty. She had dry rough skin and stunted growth for a long time.
On examination, the child appeared pale, moderately anaemic, dry rough skin all over the body, her height was 1.19 meter, weight 20 kilograms (below 4th percentile, according to CDC growth charts), heart rate was 96 per minute, blood pressure was 90/60 mm of $\mathrm{Hg}$. Breasts were at Tanner stage-1, axillary and pubic hair was absent. Lower abdomen was mildly distended, a lump about 10x12cm was felt, neurological and ophthalmological examinations were normal. Per vaginal examination revealed normal external genitalia for her age and local trauma was excluded. In view of short stature an initial impression of isosexual precocity caused by hypothyroidism was made.

Investigations revealed haemoglobin $7.5 \mathrm{gm} / \mathrm{dl}$, total leucocyte count 4400 /cumm, platelet count 270,000/cumm. There was macrocytic hypocromic anaemia in peripheral blood smear. Thyroid function showed gross hypothyroidism with serum TSH level $48.5 \mu \mathrm{IU} / \mathrm{mL}$ (normal: 0.4-5.5 $\mu \mathrm{IU} / \mathrm{mL})$, serum FT3 $0.98 \mathrm{pg} / \mathrm{mL}$ (normal-1.4-4.2 pg/ml), FT4 $0.22 \mathrm{pg} / \mathrm{mL}$ (normal-0.8-2.5pg/ml). Serum antithyroid peroxidase antibody $32 \mathrm{IU} / \mathrm{L}$ (normal $<40 \mathrm{IU} / \mathrm{L}$ ), FSH level $1.28 \mathrm{mIU} / \mathrm{mL}$ (normal 3.02-12.0 $\mathrm{mIU} / \mathrm{mL}$ in follicular phase), LH was $1.42 \mathrm{mIU} / \mathrm{mL}$ (normal 0.5-10.50 mIU/mL). Serum prolactin and CA-125 levels were raised, prolactin $33.6 \mathrm{ng} / \mathrm{ml}$ (normal 1.20-19.5ng/mL) and CA 125 $62.5 \mathrm{U} / \mathrm{ml}$ (normal $<35 \mathrm{U} / \mathrm{mL}$ ). Her bone age corresponded with chronological age. Pelvic USG revealed bulky uterus with bilateral cystic ovarian tumour, right one about $8 \times 10 \mathrm{~cm}$ and left one about $8 \times 6 \mathrm{~cm}$. USG of thyroid gland showed mild reduction in echogenicity with normal volume for age. CT scan of brain showed normal study.

Levothyroxine $5 \mathrm{ug} / \mathrm{kg} /$ day was initiated and 3 units of blood were transfused. There was no recurrence of vaginal bleeding during the follow up at 8,16 and 24 week, TSH level was 32 $\mu \mathrm{IU} / \mathrm{mL}, 24 \mu \mathrm{IU} / \mathrm{mL}$ and $4 \mu \mathrm{IU} / \mathrm{mL}$ respectively. Repeat USG 2 months later demonstrated no cyst. 
She has remained symptom free and showed a catch up growth, increase of $8 \mathrm{~cm}$ over 1 year follow up.

\section{Discussion}

Delayed pubertal development is a common manifestation of long standing untreated hypothyroidism. 5,6 But the association between early pubertal development and primary hypothyroidism was first described over 40 years ago with many reports since then. ${ }^{7}$ But there are no report on frequency of this condition. In 1960 Van Wyk and Grumbach first described a syndrome characterized by breast development, multi cystic ovary and uterine bleeding in the presence of long standing primary hypothyroidism. ${ }^{7-9}$ In these cases patient is phenotypically hypothyroid and has decreased linear growth, quite opposite of what is seen in patients with true precocious puberty. The typical clinical clues of short stature and dry rough skin were present in our case, so diagnosis of hypothyroidism could be easily entertained after excluding local causes of bleeding. In addition, important manifestations that were reported previously and detected in our case as well were bilateral ovarian enlargement. This association of precocious pubertal development and hypothyroidism, although seemingly unphysiologic, may occur in almost $50 \%$ of children with severe hypothyroidism of long duration. ${ }^{6}$ The cause of hypothyroidism in these patients may be congenital. There are different underlying hormonal mechanisms in hypothyroidism-associated precocity. Wyk and Grumbach tried to explain precocious puberty by an overlap in negative feedback regulation with overproduction of gonadotropins as well as thyrotropin (both share common $\alpha$ subunit) in response to thyroid deficiency, ${ }^{9}$ but in this case the gonadotropins were not raised, the cause behind this finding remains unexplainable. Another theory is that extreme TSH elevation seen in profound hypothyroidism induces FSH like effects on the gonads resulting in multicystic ovaries, uterine bleeding, and breast enlargement that correspond to the current case. According to prolactin theory, hyperprolactinemia as a result of chronic stimulation of TRH enhances the sensitivity of ovaries to even trace amounts of gonadotropins prepubertally ${ }^{10}$ that also goes in favour of the present case.

In conclusion, early recognition and initiation of thyroid hormone replacement can resolve symptoms, and avoid further diagnostic procedure, fear of malignancy and unnecessary surgery in such cases.

\section{References}

1. Styne DM, Grumbach MM. Puberty: Ontogeny, Neuroendocrinology, Physiology and Disorders. In: Melmed S, Polonsky K, Larsen PR, editors. William's Textbook of Endocrinology. 11th ed. Philadelphia: Saunders; 2007. p.969-1166.

2. Taher BM, Ajlouni HK, Hamamy HA, Shegem NS, Madanat AY, Ajlouni KM. Precocious Puberty at an Endocrine Centre in Jordan. Eur J Clin Invest. 2004;34:599-604.

3. Thackray VG, Mellon PL, Coss D. Hormones in Synergy: Regulation of the Pituitary Gonadotropin Genes. Molecular Cellular Endocrinol. 2010;314:192-203.

4. Wormsbecker A, Clarson C. Acquired Primary Hypothyroidism: Vaginal Bleeding in a Quiet Child. CMAG. 2010;182:588-90.

5. Bassam T, Ajlouni K. A Case of Ovarian Enlargement in Severe Primary Hypothyroidism and Review of the Literature. Ann Saudi Med. 2006;26(1):66-68.

6. Sharma Y, Bajpai A, Mittal S, Kabra M, Menon PSN. Ovarian Cysts in Young Girls with Hypothyroidism: Follow Up and Effect of Treatment. J Pediatr Endocrinol Metab. 2006;19:895-900.

7. Durbin KL, Diaz-Montes T, Loveless MB. Van Wyk and Grumbach Syndrome: An Unusual Case and Review of the Literature. J Pediatr Adolescent Gynaecol. 2011;24:93-96. 
8. Rastogi A, Bhadada SK, Bhansali A. An Unusual Presentation of a Usual Disorder: Van Wyk-Grumbach Syndrome. Indian Journal of Endocrinology and Metabolism. 2011;15(Suppl 2):S141.

9. Hunold A, Alzen G, Wudy SA, Sawatzki BR, Landmann E, Reiter A, et al. Ovarian Tumour in a
12-Year Old Female with Severe Hypothyroidism: A Case of Van Wyk and Grumbach Syndrome. Pediatr Blood Cancer. 2009;52:677-79.

10. Van Wyk JJ, MM Grumbach. Syndrome of Precocious Menstruation and Galactorrhea in Juvenile Hypothyroidism: An Example of Hormonal Overlap in Pituitary Feedback. The Journal of Pediatrics. 1960;5(3):416-35. 